\title{
Effects of Exogenous Corticosterone on Circulating Leukocytes of a Salamander (Ambystoma talpoideum) with Unusually Abundant Eosinophils
}

\author{
Andrew K. Davis and John C. Maerz \\ D. B. Warnell School of Forestry and Natural Resources, The University of Georgia, Athens, GA 30602, USA \\ Correspondence should be addressed to Andrew K. Davis, akdavis@uga.edu
}

Received 15 September 2009; Revised 19 December 2009; Accepted 12 January 2010

Academic Editor: Greg Demas

Copyright (c) 2010 A. K. Davis and J. C. Maerz. This is an open access article distributed under the Creative Commons Attribution License, which permits unrestricted use, distribution, and reproduction in any medium, provided the original work is properly cited.

When animals become stressed, their levels of glucocorticoid hormones increase, causing white blood cells to move from tissues to circulation or vice versa. The primary alteration is an increase in the abundance of circulating neutrophils and a decrease in lymphocytes in circulation. A lesser-known effect is a decrease in the number of circulating eosinophils. Salamanders in the genus Ambystoma have unusually high numbers of circulating eosinophils, and as such, any effect of stress hormones on circulating leukocytes (especially eosinophils) of these species should be especially pronounced. We conducted an experiment to determine the effect of corticosterone administration on leukocyte counts (from blood smears) of A. talpoideum salamanders. Salamanders were captured and sampled as reference animals $(n=11)$, given a sham injection $(n=8)$, or injected with $0.1 \mathrm{cc}$ of a $100 \mu \mathrm{g} / \mathrm{mL}$ corticosterone solution $(n=28)$. After 24 hours, relative neutrophil counts were higher and relative lymphocyte counts lower, in the corticosterone group than the sham and control groups. Absolute counts showed that this effect was driven by a reduction in lymphocytes, since neutrophil counts were statistically similar across treatments. Importantly, relative and absolute numbers of eosinophils decreased in the sham and corticosterone groups, confirming the sensitivity of this cell to stress in amphibians.

\section{Introduction}

In all vertebrates, acute stress-related increases in glucocorticoid hormones affect multiple physiological systems in the body, such as increasing heart rate to speed delivery of blood to tissues and promoting gluconeogenesis to increase energy reserves, actions which are thought to promote survival during stress events (reviewed in [1]). Glucocorticoids also influence the numbers of circulating white blood cells. This effect has been well-studied in many taxa including mammals [2-5], amphibians [6-8], reptiles [9], fish [10, 11], and birds [12-14]. In most cases, increases in glucocorticoid hormones leads to an increase in the number of neutrophils (or heterophils in birds and reptiles) in circulation and a decrease in the number of lymphocytes in circulation. The increase in neutrophil abundance occurs via a combination of cell migration from tissues into circulation along with increased production from hemopoeitic tissue and extension of cell lifespan, while lymphocytes are thought to migrate from circulation into lymphoid tissue $[15,16]$. This process is thought to temporarily redistribute important cell types to where they would be most needed during particularly harsh or "stressful" conditions $[3,17,18]$. Since neutrophils are phagocytic and target foreign particles and microbes, their accumulation in the bloodstream during stress events would allow them to be rapidly mobilized in response to injuries or infections. The significance of the reduction in circulating lymphocytes, which are responsible for cellmediated immunity and cytokine responses [19], is less clear. Regardless of the reason however, this effect conveniently provides a way for animal ecologists to use the ratio of neutrophils (or heterophils) to lymphocytes (N:L or $\mathrm{H}: \mathrm{L}$ ratio) as an indirect index of the level of plasma glucocorticoids in study animals (reviewed in [20]), since the ratio is positively related to the magnitude of the stress event [12]. 


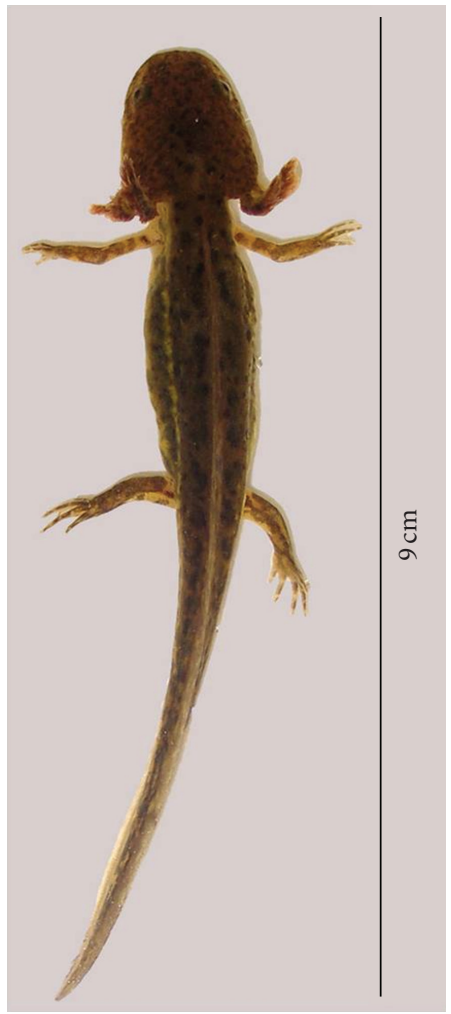

(a)

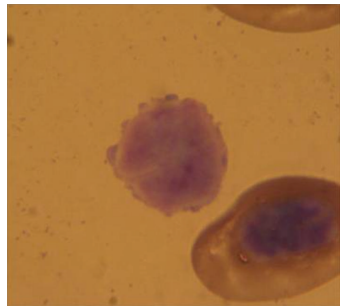

(b)

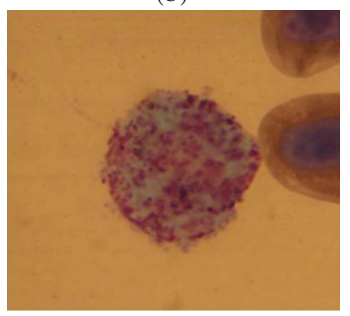

(d)

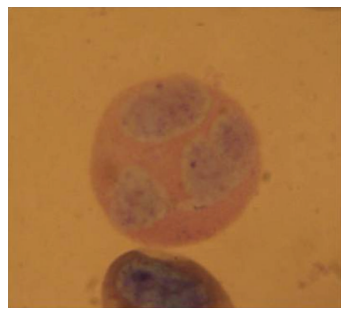

(f)

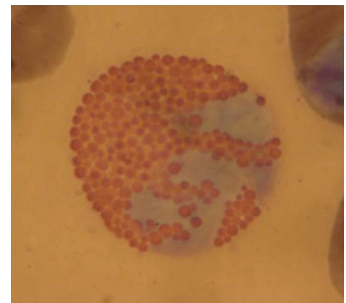

(c)

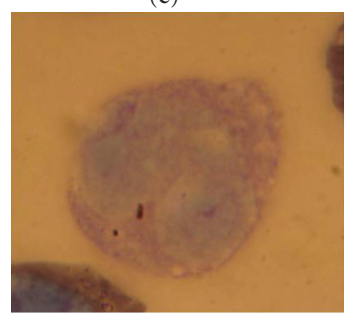

(e)

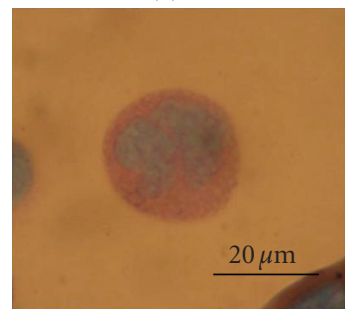

(g)

FIgUre 1: (a) Paedogenic mole salamander, Ambystoma talpoideum, and leukocytes typical of this species after giemsa staining and at 1000X: (b) lymphocyte, (c) eosinophil with typical rounded, orange-staining granules, (d) basophil with diffuse, purple-staining granules, (e) monocyte, showing grey-blue cytoplasm with some vaculation, (f) normal neutrophil with three nuclear lobes and pink-staining cytoplasm, and (g) a neutrophil with foamy cytoplasm.

There is a third white blood cell type that has been shown in some taxa to be sensitive to hormones involved in the stress response-the eosinophil, although this effect is often overlooked, perhaps because this cell comprises less than $5 \%$ of the circulating leukocyte population in most species $[19,21]$. The function of eosinophils in the innate immune system has not been fully elucidated, but they are known to respond to metazoan parasite infections [19, 21, 22], and in amphibians they have a role in metamorphosis [23, 24], although the nature of this role is not known. With respect to their sensitivity to glucocorticoid hormones, the majority of studies into this effect have focused only on mammalian subjects (e.g., $[4,25,26])$. Nevertheless, these studies show that increases in glucocorticoid hormones can often cause a reduction in circulating eosinophil numbers in addition to the change in neutrophils and lymphocytes, although the reason for the reduction of circulating eosinophils (termed "eosinopenia" in veterinary and biomedical textbooks) is not known. It is also not clear how prevalent this phenomenon is in the animal kingdom. The effects of glucocorticoids on leukocytes of birds has been well-studied, especially by poultry researchers (e.g., $[12,27]$ ), but a review of the early literature on this subject, covering 66 investigations into stress and leukocytes, made no mention of an effect on circulating eosinophil numbers [28]. Furthermore, the early studies of the effects of glucocorticoids on leukocytes of amphibians mostly opted not to report the effects on eosinophils because of their low numbers in the frogs and newts studied $[29,30]$.

There is recent evidence that eosinophil numbers in certain amphibians can be affected by glucocorticoid hormones, and in fact this susceptibility may even have serious consequences for amphibian populations because of their role in the immune system. With their role in host defense against metazoan parasites in mind, Belden and Kiesecker [31] showed that exogenous administration of a glucocorticoid hormone to larval amphibians (gray treefrogs, Hyla versicolor) causes reductions in circulating eosinophil numbers which then leads to increases in trematode parasite infections, which are thought by some to be responsible for the increasing incidence of limb deformities reported in many populations (e.g., $[32,33])$. In addition, while not specifically examining effects of hormones, other work by Kiesecker [34] and Rohr et al. [35] confirmed the link between eosinophil numbers and trematode susceptibility by showing how amphibians (frog species in the genus Rana) exposed to agrochemicals have reduced eosinophil production and abundance and are more susceptible to trematode infection. We point out that while these studies highlight the importance of eosinophils in the amphibian 


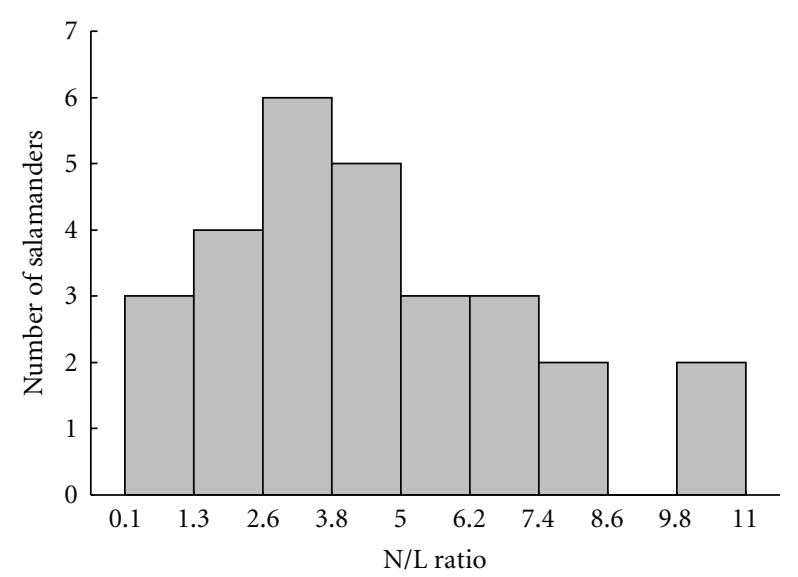

FIGURE 2: Distribution of neutrophil-lymphocyte ratios of all mole salamanders that received intraperitoneal corticosterone injections $(n=28)$.

defense against these and other parasites, in each study above, the species that were examined typically have less than $5 \%$ eosinophils in circulation [36]. Interestingly, a recent report showed that up to $50 \%$ of the circulating white blood cells in salamanders within the genus Ambystoma are eosinophils [37], which may be the highest of any species in the animal kingdom. While the reasons for this unusual abundance of eosinophils are not clear, it would be of interest to know if and to what degree the eosinophils of these animals are susceptible to hormones involved in the stress response, and how this compares to that of neutrophils and lymphocytes.

Here we describe the results of an experiment designed to answer the question above, using wild-caught, paedogenic mole salamanders, Ambystoma talpoideum (Figure 1(a)), which are common in ponds and wetlands in the southeastern United States. Eosinophils make up between 25\% to 45\% of the normal circulating white blood cell population in this species in the wild [20,38]. In this experiment, exogenous corticosterone (cort) was administered (via injection) to recently captured individuals and after a 24 hours period their circulating level of neutrophils, lymphocytes, and eosinophils was compared to levels in untreated (reference) individuals, and to those injected with a sham treatment. The results of this study will be of importance to researchers who collect white blood cell data (especially eosinophil counts) in these and other amphibians, and for further elucidating the range of effects of glucocorticoids on animal physiology.

\section{Methods}

2.1. Experimental Setup. On August 12, 2008, we captured 47 paedogenic mole salamanders from a single permanent pond in the Whitehall Experimental Forest at the University of Georgia (Athens, GA). All salamanders were captured within 20 minutes, and transported to our lab (10 minutes away) in a container of pond water. In the lab, salamanders were haphazardly divided into 3 groups: reference salamanders $(n=11)$, which provided a baseline for hematological profiles, sham injected salamanders $(n=8)$, and corticosterone injected salamanders $(n=28)$. We assigned more animals to the corticosterone injected treatment so we could evaluate the extent of variation in leukocyte response to the stress hormone injection. The haphazard assignment of salamanders did not result in biased body sizes within any treatment; the mean body mass of each group was 2.31 $( \pm 0.25 \mathrm{SD}), 2.17( \pm 0.34 \mathrm{SD})$, and $2.09( \pm 0.32 \mathrm{SD})$ grams, for the reference, sham and corticosterone groups, respectively, and these means were not significantly different (one way ANOVA: $\left.F_{2,44}=1.918, P=.159\right)$.

The reference group was processed (described below) immediately to obtain control leukocyte profiles. It is important to point out here that the effects of glucocorticoid hormones on leukocytes of ectothermic animals take hours to manifest (reviewed in [20]) such that effects of capture, handling or transport are negligible for this group since all individuals were processed within 1 hour of capture from the pond. The salamanders from the other two groups were injected with their respective solutions (described below) then held for 24 hours in $40 \mathrm{~L}$ plastic containers (7-8 individuals per container) filled with $10 \mathrm{~L}$ of tap water treated with Tetra AquaSafe water conditioner. Each container also had a layer of leaves (collected from the pond) covering the bottom, to provide the salamanders with natural cover for hiding.

Processing the salamanders from all groups was the same and followed established procedures [20, 38, 39]. For this, each individual was euthanized in a $2 \%$ MS-222 solution, and then weighed with an electronic balance. The animal was decapitated and blood from the heart region was dripped onto a clean microscope slide and a standard blood smear made. Finally, the carcass was dissected open and the sex assigned based on inspection of the reproductive organs.

2.2. Injection Solutions. Prior to collecting the salamanders, we prepared two solutions for the experimental injections. The first was a sham solution of buffered saline. The second was a solution of $100 \mu \mathrm{g} / \mathrm{mL}$ corticosterone (Sigma Aldrich) in buffered saline. Salamanders in both injection groups received an intraperitoneal injection near the left hind leg of $0.1 \mathrm{cc}$ of the designated treatment solution. This dosage of corticosterone is within the range commonly used by other amphibian researchers who study the effects of stress; Moore and Miller [40] administered corticosterone doses ranging from 10 to $250 \mu \mathrm{g} / \mathrm{mL}$ to sets of newts, and Burmeister et al. [41] administered between $100-400 \mu \mathrm{g} / \mathrm{mL}$ of corticosterone to treefrogs. Treatment animals were replaced into their container and left for 24 hours, which is the time required for any glucocorticoid hormone-induced changes in leukocyte populations to occur in amphibians $[6-8,29]$. All procedures (transport, sampling the pond animals, injections, etc.) up to this point were completed within 1 hour of capture from the pond. After 24 hours, all salamanders in the sham and corticosterone groups were processed in the same manner as the reference salamanders the day before. We note that since we did not measure endogenous levels of corticosterone in this experiment, we do not know for certain if and to what degree 
TABLE 1: Summary of leukocyte differentials of salamanders (Ambystoma talpoideum) in all treatments in this study. Shown are the average percentages $( \pm 1 \mathrm{SD})$ of each cell type out of the total number of cells, as well as the average $\mathrm{N}: \mathrm{L}$ ratio for each treatment group. Reference animals were sampled within 1 hour of capture, sham and corticosterone groups sampled 24 hours after capture and injection.

\begin{tabular}{|c|c|c|c|c|c|c|c|}
\hline \multirow{2}{*}{ Salamander group } & \multirow{2}{*}{$\mathrm{N}$} & \multicolumn{5}{|c|}{ Leukocyte type } & \multirow{2}{*}{$\mathrm{N}: \mathrm{L}$} \\
\hline & & Neutrophils & Lymphocytes & Eosinophils & Basophils & Monocytes & \\
\hline Reference & 11 & $21.3(9.9)$ & $40.5(11.7)$ & $32.0(16.1)$ & $4.9(4.8)$ & $1.3(2.1)$ & $0.56(0.29)$ \\
\hline Sham injected & 8 & $44.8(25.9)$ & $17.7(7.5)$ & $27.5(24.2)$ & $5.8(6.0)$ & $4.1(3.0)$ & $2.17(1.66)$ \\
\hline Corticosterone injected & 28 & $54.9(19.7)$ & $17.2(19.8)$ & $19.8(18.9)$ & $4.3(3.7)$ & $3.8(3.1)$ & $4.42(2.67)$ \\
\hline
\end{tabular}

the final hormone level of the corticosterone salamanders was greater than the sham and reference group. However, based on results from prior work where similar hormone doses were administered to similarly-sized amphibians and where endogenous levels were in fact measured [41], we logically assume that the administration of corticosterone here acted to raise endogenous corticosterone above resting levels, thereby mimicking a stress response in the target salamanders.

2.3. Leukocyte Counting. Procedures for reading salamander blood smears and counting leukocytes were typical of those used by us in prior studies of birds [14, 38, 42] and amphibians [20, 24, 38]. Briefly, dried blood smears were stained with giemsa, and then examined under $1000 \times$ with a standard light microscope. The smear was scanned in a standard zig-zag pattern and fields of view with even distributions of red blood cells were selected for counting. At this magnification and for this species, the average number of erythrocytes per field was $32.2 \pm 8.7 \mathrm{SD}$ (based on counts from 25 random fields; Davis, unpublished data). All white blood cells were tallied in each field until at least 100 cells had been counted. Cells were identified as neutrophils, lymphocytes, eosinophils, basophils, and monocytes (Figures 1(b)-1(g)), following Thrall [43], Turner [44] and HadjiAzimi et al. [45], although the focus here was on the first three cell types. The relative number of each cell type was calculated (i.e., the percentage, based on the total number of white blood cells counted), and we calculated the ratio of neutrophils to lymphocytes $(\mathrm{N}: \mathrm{L})$ for each salamander based on the percentages of these cells $[14,20,38,46]$. We also calculated the number of each cell per 10 fields of view to use as an absolute estimate of the number of each cell type in circulation $[47,48]$.

2.4. Data Analysis. We examined the effect of corticosterone on absolute numbers of neutrophils, lymphocytes, and eosinophils (all log-transformed +1 ) using ANCOVA, where the cell count was the response variable, treatment (reference, sham or cort) and sex were the categorical explanatory variables, and body mass was a continuous covariate, to account for any possible size or ontogenetic-related effects on leukocyte profiles. Interaction terms were initially included in the models, but removed if not significant. Analyses were conducted using Statistica 6.1 software [49].

\section{Results}

3.1. Relative Cell Counts. Across all 47 individuals, the relative numbers of each white blood cell type showed a profile typical of Ambystomatid salamanders, in that eosinophils made up nearly a third of all white blood cells (Table 1, [37]). While we did not perform statistical analyses on relative cell counts (only absolute numbers were analyzed), it is evident from Table 1 that the relative numbers of neutrophils, lymphocytes, and eosinophils differed visibly across treatments. The mean percentage of neutrophils increased from $21.3 \%$ in the salamanders sampled within one hour of capture, to $44.8 \%$ in the sham injection group, and $54.9 \%$ in the corticosterone injection group. The mean percentage of lymphocytes decreased from $40.5 \%$ in the reference animals to $17.7 \%$ and $17.2 \%$ in the experimental groups. The mean percentage of eosinophils also decreased from $32 \%$ in the reference group to $27.5 \%$ in the sham and $19.8 \%$ in the cort group. Interestingly, one salamander in the sham group appeared to have an extremely atypical leukocyte profile, as $75.8 \%$ of its white blood cells were neutrophils and only $4.2 \%$ were lymphocytes. There was nothing unusual about this individual noted during processing that we can attribute to this deviation, such as an injury or missing appendages. Nevertheless, these extreme values led to an especially high $\mathrm{N}$ : L ratio for this individual (18.0), which was over two-standard deviations above the mean for that group (2.17, Table 1). We conducted subsequent analyses of absolute neutrophil and lymphocyte counts with and without this individual so we could characterize the effect of this individual on subsequent inferences. Regarding the $\mathrm{N}: \mathrm{L}$ ratios of the corticosterone group, there was considerable variation in $\mathrm{N}$ : $\mathrm{L}$ ratios among salamanders. Of the 28 individuals receiving the single dose of corticosterone $(0.1 \mathrm{cc}$ of a $100 \mu \mathrm{g} / \mathrm{mL}$ concentration), $\mathrm{N}$ : L ratios varied from 0.13 to 11.0 , and showed an approximate normal distribution (Figure 2).

3.2. Effects on Absolute Cell Counts. With the one outlier included, the initial ANCOVA model examining factors influencing neutrophil abundance revealed no significant interaction effects between treatment, sex or body mass $(P>.05$ for all). In a model with main effects only, there was no significant effect of treatment $\left(F_{2,42}=0.263, P=\right.$ $.770)$, nor of sex $\left(F_{1,42}=2.734, P=.106\right)$, but an effect of body size $\left(F_{1,42}=4.566, P=.038\right)$. With the 


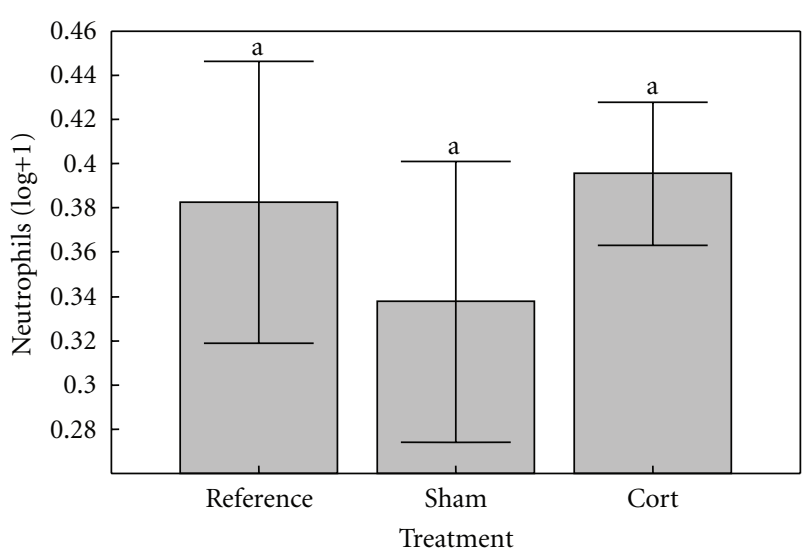

(a)

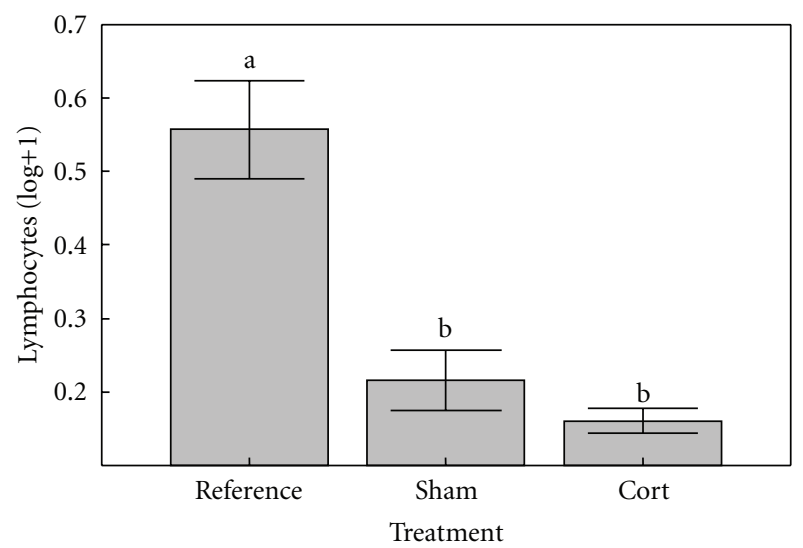

(b)

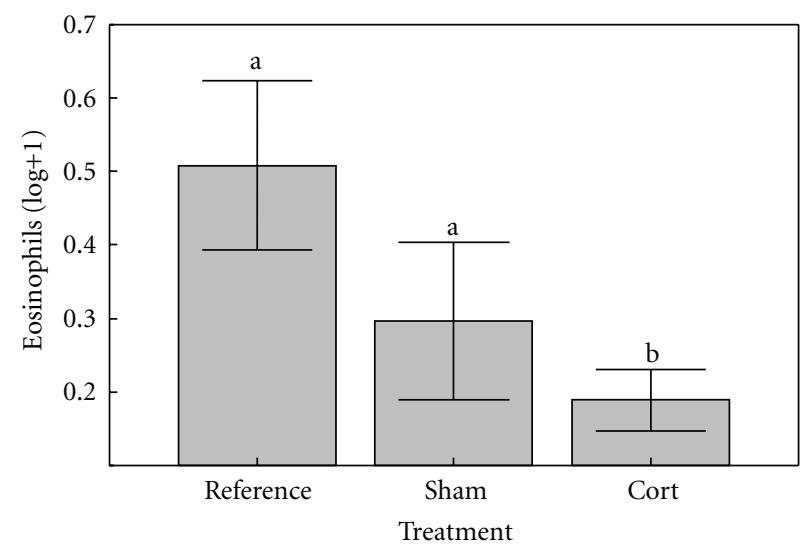

(c)

FIGURE 3: Effects of sham injection and corticosterone (cort) injection on absolute estimates of circulating neutrophil (a), lymphocyte (b), and eosinophil (c) abundance in mole salamanders. Shown are the log-transformed mean ( $\pm 1 \mathrm{SE}$ ) abundance estimates for each cell (i.e., numbers of cells per 10 fields of view). Letters above the bars indicate statistically significant groups, based on Tukey's HSD tests.

outlier excluded, there were no significant interaction terms, and the main effects model showed similar results: there was no effect of treatment $\left(F_{2,41}=0.760, P=.474\right.$; Figure 3(a)) or sex $\left(F_{1,41}=2.411, P=.128\right)$, but an effect of body size $\left(F_{1,41}=5.038, P=.030\right)$. The relationship between body size and neutrophil abundance was positive, but weakly so (Pearson correlation, $r=0.26, P=.084$ ). With the outlier included, the model examining lymphocyte abundance showed no significant interaction terms $(P>.05$ for all), and the model with main effects only showed no significant variation between sexes $\left(F_{1,42}=3.277, P=.077\right)$, but significant effects of treatment $\left(F_{2,42}=33.031, P<\right.$ $.001)$ and body size $\left(F_{1,42}=4.459, P=.041\right)$. The results were similar with the outlier excluded; the main effects model showed significant effects of body size $\left(F_{1,41}=\right.$ 4.429, $P=.041)$ and treatment $\left(F_{2,41}=32.431, P<\right.$ .001). In the treatment effect, Tukey's HSD tests showed that the sham and cort groups had significantly lower numbers of lymphocytes than the reference group $(P<$ .001 for both), but they were not significantly different themselves $(P=.566$; Figure $3(\mathrm{~b}))$. The effect of body size on lymphocyte abundance was positive (Pearson correlation, $r=0.37, P=.012)$. Finally, in the initial ANCOVA model examining variation in eosinophil abundance there was no support for inclusion of any interaction term $(P>$ .05 for all). In the main effects only model, there was no variation between sexes $\left(F_{1,42}=0.060, P=.807\right)$, a weak trend with body size $\left(F_{1,42}=3.612, P=.064\right)$, and importantly, a significant effect of treatment $\left(F_{2,42}=\right.$ $3.536, P=.038)$. Tukey's HSD tests showed that the shaminjected salamanders had statistically similar numbers of eosinophils as did the reference salamanders $(P=.180)$, but cort-injected salamanders had significantly lower numbers of eosinophils than did the reference individuals $(P=$ .005). The numbers of eosinophils in corticosterone-injected salamanders were statistically similar to those of the shaminjected salamanders $(P=.642$; Figure $3(\mathrm{c}))$.

\section{Discussion}

The results of this experiment demonstrated that both capture and administration of exogenous corticosterone causes alterations in the leukocyte profile of paedogenic mole salamanders. Consistent with studies of most other animal taxa [20], the ratio of neutrophils to lymphocytes reflected the different levels of stress in each treatment; the average $\mathrm{N}: \mathrm{L}$ ratio was higher among sham-injected salamanders than among reference salamanders (presumably reflecting the natural rise in corticosterone after these activities), and higher still among corticosterone injected salamanders than among sham and reference salamanders (Table 1). Interestingly though, comparing absolute numbers of both neutrophils and lymphocytes showed that this trend was being driven largely by a decrease in circulating lymphocyte numbers (Figure 3(b)), while absolute neutrophil levels stayed more or less constant across treatments (Figure 3(a)). In fact, the estimated count of lymphocytes decreased dramatically, from a mean of 3.1 cells per 10 microscope fields in the reference salamanders (i.e., before log-transformation) to 0.7 in the sham and 0.5 in the cort groups, which is equivalent to an $84 \%$ drop overall in the circulating numbers of this cell.

The numbers of circulating eosinophils in this amphibian species appeared to be influenced by the stress treatments as 
well, although the only significant difference among treatment groups was between the reference and corticosterone groups. Still, the average counts of eosinophils dropped from a mean of 3.8 cells per 10 microscope fields in the reference group, to 1.4 cells in the sham group and 0.8 cells in the corticosterone group (Figure 3(c)). Thus, the magnitude of the overall difference between the eosinophil counts in reference salamanders and cort-injected salamanders was equivalent to a $79 \%$ drop in circulating numbers, which is of similar magnitude as the drop in estimated lymphocyte numbers. Interestingly, since eosinophils make up such a large proportion of the white blood cell population in this species, the large drop in eosinophil numbers combined with the equally-large decrease in lymphocyte numbers no doubt both contributed to the apparent increase in relative neutrophil numbers in the sham and cort treatments (Table 1), when in fact the absolute numbers of this cell did not necessarily increase (Figure 3(a)). In this case, the fewer numbers of lymphocytes and eosinophils in these treatments made neutrophils the most abundant cell type (Table 1), even though absolute neutrophils numbers did not increase. Thus, future studies involving white blood cell counts in this and other Ambystomatid species with abundant eosinophils should consider the impact of the eosinophil numbers on the commonly-used neutrophil-lymphocyte ratio.

From an additional methodological standpoint, the sensitivity of eosinophils to variations in stress hormones could be of utility to researchers who routinely collect white blood cell data, in that it could aid in the interpretation of such data and help discriminate between a stress response and an inflammation or disease response [50]. For example, since neutrophils (or heterophils in birds and reptiles) can increase in number in response to infection $[19,21,22]$ but also in response to general stress [50], interpreting high neutrophil counts in study subjects can be particularly challenging. However, if the increased neutrophil count is seen along with reductions in lymphocytes and/or eosinophils, a researcher could more easily interpret this to be a stress response, consistent with increasing levels of glucocorticoid hormones. An example of this challenge within amphibians is a recent study of the effects of the fungal disease, chytridiomycosis, on leukocyte counts in frog larvae [48]. Results of that study indicated that infected larvae had increased neutrophil numbers in circulation, consistent with either inflammation or stress. There was no change in lymphocyte numbers, but infected larvae did have a significant reduction in circulating eosinophils, which based on the current results, is consistent with increased stress in the infected group, as opposed to an inflammation response, which is not usually associated with reductions in eosinophil counts $[19,21,22]$. Since infections can compromise mouthparts and therefore feeding ability in anuran larvae [51], it is possible that infection of this disease in larvae leads to reductions in food intake, which is known to cause increases in glucocorticoid hormones [52].

As a final point, our results indicate that the sensitivity of eosinophils to stress should be kept in mind in studies where these cells are counted to serve as a measure of parasite susceptibility, especially if the amphibians under study inhabit, or are reared under, potentially stressful conditions or environments, such as could occur with exposure to pesticides and agrochemicals (e.g., [34, 35]). In these studies, chemical exposure tends to reduce eosinophil production or circulating abundance, and the assumption is that the chemicals caused the reduction (i.e., by impairing or "suppressing" immune function). Results from the current study indicate that an endogenous stress response to the chemicals, not the chemicals per se, can cause the same result. In fact, given the unusual abundance of eosinophils in Ambystomatid salamanders, the hormonally-induced reductions of both lymphocytes and eosinophils (which combined make up at least $50 \%$ of the white blood cell population in these amphibians) could even explain the reduction in total white blood cell numbers seen recently in Ambystoma tigrinum salamanders after exposure to the herbicide, atrazine [47]. Lastly, while not specifically addressing parasite susceptibility, field surveys by Raffel et al. [53] showed how counts of both lymphocytes and eosinophils in newts decreased with decreasing water temperature, while there was little effect on neutrophil abundance. The idea that stress could cause these patterns was dismissed in that paper, but the similarity of those results to the current study may not be coincidental. In any case, these examples emphasize how important it is that animal and wildlife researchers have a thorough understanding of the effects of stress on leukocyte counts.

\section{Acknowledgments}

The authors would like to thank two anonymous reviewers for providing helpful comments on the manuscript. AKD was supported by funding from the D.B. Warnell School of Forestry and Natural Resources at the University of Georgia and the Morris Animal Foundation during this project. All procedures in this study were approved by the UGA Animal Care and Use Committee (AUP no.A2009-10120).

\section{References}

[1] J. C. Wingfield and L. M. Romero, "Adrenocortical responses to stress and their modulation in free-living vertebrates," in Coping with the Environment: Neural and Endocrine Mechanisms, B. S. McEwen and H. M. Goodman, Eds., vol. 4 of Handbook of Physiology, Section 7: The Endocrine System, pp. 211-234, Oxford University Press, New York, NY, USA, 2001.

[2] P. D. Rossdale, P. N. Burguez, and R. S. Cash, "Changes in blood neutrophil/lymphocyte ratio related to adrenocortical function in the horse," Equine Veterinary Journal, vol. 14, no. 4, pp. 293-298, 1982.

[3] F. S. Dhabhar, A. H. Miller, B. S. McEwen, and R. L. Spencer, "Stress-induced changes in blood leukocyte distribution-role of adrenal steroid hormones," Journal of Immunology, vol. 157, no. 4, pp. 1638-1644, 1996.

[4] B. H. Anderson, D. L. Watson, and I. G. Colditz, "The effect of dexamethasone on some immunological parameters in cattle," Veterinary Research Communications, vol. 23, no. 7, pp. 399413, 1999.

[5] C.-Y. Kim, J. S. Han, T. Suzuki, and S.-S. Han, "Indirect indicator of transport stress in hematological values in newly 
acquired cynomolgus monkeys," Journal of Medical Primatology, vol. 34, no. 4, pp. 188-192, 2005.

[6] M. F. Bennett and J. K. Alspaugh, "Some changes in the blood of frogs following administration of hydrocortisone," The Virginia Journal of Science, vol. 15, pp. 76-79, 1964.

[7] M. F. Bennett and J. A. Harbottle, "The effects of hydrocortisone on the blood of tadpoles and frogs, Rana catesbeiana," Biological Bulletin, vol. 135, no. 1, pp. 92-95, 1968.

[8] M. F. Bennett, C. A. Gaudio, A. O. Johnson, and J. H. Spisso, "Changes in the blood of newts, Notophthalmus viridescens, following the administration of hydrocortisone," Journal of Comparative Physiology A, vol. 80, no. 2, pp. 233-237, 1972.

[9] J. S. Wojtaszek, "The effect of cortisol on the circulating blood parameters and on the activity of alanine and aspartate aminotransferases in the grass snake Natrix natrix natrix L.," Comparative Biochemistry and Physiology A, vol. 105, no. 2, pp. 259-266, 1993.

[10] M. F. Bennett and C. Gaudio Neville, "Effects of cold shock on the distribution of leukocytes in goldfish, Carassius auratus," Journal of Comparative Physiology A, vol. 98, pp. 213-216, 1975.

[11] J. Wojtaszek, D. Dziewulska-Szwajkowska, M. LozinskaGabska, A. Adamowicz, and A. Dugaj, "Hematological effects of high dose of cortisol on the carp (Cyprinus carpio L.): cortisol effect on the carp blood," General and Comparative Endocrinology, vol. 125, no. 2, pp. 176-183, 2002.

[12] W. B. Gross and H. S. Siegel, "Evaluation of the heterophil/lymphocyte ratio as a measure of stress in chickens," Avian Diseases, vol. 27, no. 4, pp. 972-979, 1983.

[13] J. Moreno, S. Merino, J. Martinez, J. J. Sanz, and E. Arriero, "Heterophil/lymphocyte ratios and heat-shock protein levels are related to growth in nestling birds," Ecoscience, vol. 9, no. 4, pp. 434-439, 2002.

[14] A. K. Davis, "Effect of handling time and repeated sampling on avian white blood cell counts," Journal of Field Ornithology, vol. 76, no. 4, pp. 334-338, 2005.

[15] H. Engler, M. T. Bailey, A. Engler, and J. F. Sheridan, "Effects of repeated social stress on leukocyte distribution in bone marrow, peripheral blood and spleen," Journal of Neuroimmunology, vol. 148, no. 1-2, pp. 106-115, 2004.

[16] M. D. Trottier, M. M. Newsted, L. E. King, and P. J. Fraker, "Natural glucocorticoids induce expansion of all developmental stages of murine bone marrow granulocytes without inhibiting function," Proceedings of the National Academy of Sciences of the United States of America, vol. 105, no. 6, pp. 2028-2033, 2008.

[17] F. S. Dhabhar, A. H. Miller, M. Stein, B. S. Mcewen, and R. L. Spencer, "Diurnal and acute stress-induced changes in distribution of peripheral blood leukocyte subpopulations," Brain, Behavior, and Immunity, vol. 8, no. 1, pp. 66-79, 1994.

[18] F. S. Dhabhar, A. H. Miller, B. S. McEwen, and R. L. Spencer, "Effects of stress on immune cell distribution-dynamics and hormonal mechanisms," Journal of Immunology, vol. 154, no. 10, pp. 5511-5527, 1995.

[19] M. A. Thrall, D. C. Baker, E. D. Lassen, et al., Veterinary Hematology and Clinical Chemistry, Blackwell, Ames, Iowa, USA, 2006.

[20] A. K. Davis and J. C. Maerz, "Sex-related differences in hematological stress indices of breeding, paedomorphic mole salamanders," Journal of Herpetology, vol. 42, pp. 197-201, 2008.

[21] N. C. Jain, Essentials of Veterinary Hematology, Blackwell, Philadelphia, Pa, USA, 1993.
[22] S. L. Stockham and M. A. Scott, Fundamentals of Veterinary Clinical Pathology, Blackwell, Ames, Iowa, USA, 2002.

[23] A. P. Ussing and P. Rosenkilde, "Effect of induced metamorphosis on the immune system of the axolotl, Ambystoma mexicanum," General and Comparative Endocrinology, vol. 97, no. 3, pp. 308-319, 1995.

[24] A. K. Davis, "Metamorphosis-related changes in leukocyte profiles of larval bullfrogs (Rana catesbeiana)," Comparative Clinical Pathology, vol. 18, pp. 181-186, 2009.

[25] M. P. McGarry, "Hydrocortisone acetate induced eosinopenia in mice: independence from the thymus," Cellular Immunology, vol. 29, no. 2, pp. 347-352, 1977.

[26] K. Noda, M. Aoki, H. Akiyoshi, et al., "Effect of bovine lactoferrin on the immune responses of captive bottlenosed dolphins (Tursiops truncatus) being transported over long distances," Veterinary Record, vol. 159, no. 26, pp. 885-888, 2006.

[27] J. M. McFarlane, S. E. Curtis, J. Simon, and O. A. Izquierdo, "Multiple concurrent stressors in chicks. 2. Effects on hematologic, body composition, and pathologic traits," Poultry Science, vol. 68, no. 4, pp. 510-521, 1989.

[28] M. H. Maxwell, "Avian blood leukocyte responses to stress," Worlds Poultry Science Journal, vol. 49, pp. 34-43, 1993.

[29] M. F. Bennett and N. C. Newell, "A further study of the effects of hydrocortisone on the blood of frogs," The Virginia Journal of Science, vol. 16, pp. 128-130, 1965.

[30] M. F. Bennett and L. E. Reap, "Photoperiod, stress and the distribution of leukocytes in the peripheral blood of Notophthalmus viridescens," Journal of Comparative Physiology A, vol. 125, no. 3, pp. 205-207, 1978.

[31] L. K. Belden and J. M. Kiesecker, "Glucocorticosteroid hormone treatment of larval treefrogs increases infection by Alaria sp trematode cercariae," Journal of Parasitology, vol. 91, pp. 686-688, 2005.

[32] P. T. J. Johnson, E. R. Preu, D. R. Sutherland, J. M. Romansic, B. Han, and A. R. Blaustein, "Adding infection to injury: synergistic effects of predation and parasitism on amphibian malformations," Ecology, vol. 87, no. 9, pp. 2227-2235, 2006.

[33] R. S. Rajakaruna, P. Piyatissa, U. A. Jayawardena, A. N. Navaratne, and P. H. Amerasinghe, "Trematode infection induced malformations in the common hourglass treefrogs," Journal of Zoology, vol. 275, no. 1, pp. 89-95, 2008.

[34] J. M. Kiesecker, "Synergism between trematode infection and pesticide exposure: a link to amphibian deformities in nature?" Proceedings of the National Academy of Sciences, vol. 99, pp. 9900-9904, 2002.

[35] J. R. Rohr, A. M. Schotthoefer, T. R. Raffel, et al., "Agrochemicals increase trematode infections in a declining amphibian species," Nature, vol. 455, no. 7217, pp. 1235-1239, 2008.

[36] A. K. Davis, "The Wildlife Leukocytes Website: the ecologist's source for information about leukocytes of wildlife species," 2009, http://www.wildlifehematology.uga.edu/.

[37] A. K. Davis and A. M. Durso, "Leukocyte differentials of northern cricket frogs (Acris c. crepitans) with a compilation of published values from other amphibians," Herpetologica, vol. 65, pp. 260-267, 2009.

[38] A. K. Davis and J. C. Maerz, "Comparison of hematological stress indicators in recently captured and captive paedomorphic mole salamanders, Ambystoma talpoideum," Copeia, vol. 2008, pp. 613-617, 2008.

[39] A. K. Davis and J. C. Maerz, "Effects of larval density on hematological stress indices in salamanders," Journal of Experimental Zoology A, vol. 311, no. 9, pp. 697-704, 2009. 
[40] F. L. Moore and L. J. Miller, "Stress-induced inhibition of sexual behavior: corticosterone inhibits courtship behaviors of a male amphibian (Taricha granulosa)," Hormones and Behavior, vol. 18, no. 4, pp. 400-410, 1984.

[41] S. Burmeister, C. Somes, and W. Wilczynski, "Behavioral and hormonal effects of exogenous vasotocin and corticosterone in the green treefrog," General and Comparative Endocrinology, vol. 122, no. 2, pp. 189-197, 2001.

[42] A. K. Davis, K. C. Cook, and S. Altizer, "Leukocyte profiles of House Finches with and without mycoplasmal conjunctivitis, a recently emerged bacterial disease," Ecohealth, vol. 1, pp. 362-373, 2004.

[43] M. A. Thrall, "Hematology of amphibians," in Veterinary Hematology and Clinical Chemistry: Text and Clinical Case Presentations, M. A. Thrall, D. C. Baker, and E. D. Lassen, Eds., Lippincott Williams \& Wilkins, Philadelphia, Pa, USA, 2004.

[44] R. J. Turner, "Vertebrate blood cells," in Amphibians, A. F. Rawley and N. A. Ratcliffe, Eds., pp. 129-209, Cambridge University Press, Cambridge, UK, 1988.

[45] I. Hadji-Azimi, V. Coosemans, and C. Canicatti, "Atlas of adult Xenopus laevis laevis hematology," Developmental and Comparative Immunology, vol. 11, no. 4, pp. 807-874, 1987.

[46] A. K. Davis, N. E. Diggs, P. P. Marra, and R. J. Cooper, "Hematological stress indices show no effect of radio-transmitters on wintering Hermit Thrushes," Journal of Field Ornithology, vol. 79, pp. 293-297, 2008.

[47] D. Forson and A. Storfer, "Atrazine increases ranavirus susceptibility in the tiger salamander, Ambystoma tigrinum," Ecological Applications, vol. 16, no. 6, pp. 2325-2332, 2006.

[48] A. K. Davis, M. K. Keel, A. Ferreira, and J. C. Maerz, "Effects of chytridiomycosis on circulating white blood cell distributions of bullfrog larvae (Rana catesbeiana)," Comparative Clinical Pathology, vol. 19, no. 1, pp. 49-55, 2010.

[49] Statistica, Statistica version 6.1, Statsoft Inc, 2003.

[50] A. K. Davis, D. L. Maney, and J. C. Maerz, "The use of leukocyte profiles to measure stress in vertebrates: a review for ecologists," Functional Ecology, vol. 22, pp. 760-772, 2008.

[51] C. L. Rowe, O. M. Kinney, A. P. Fiori, and J. D. Congdon, "Oral deformities in tadpoles (Rana catesbeiana) associated with coal ash deposition: effects on grazing ability and growth," Freshwater Biology, vol. 36, no. 3, pp. 723-730, 1996.

[52] L. Kubíková, P. Výboh, and L. Koštál, "Behavioural, endocrine and metabolic effects of food restriction in broiler breeder hens," Acta Veterinaria Brno, vol. 70, pp. 247-257, 2001.

[53] T. R. Raffel, J. R. Rohr, J. M. Kiesecker, and P. J. Hudson, "Negative effects of changing temperature on amphibian immunity under field conditions," Functional Ecology, vol. 20, no. 5, pp. 819-828, 2006. 

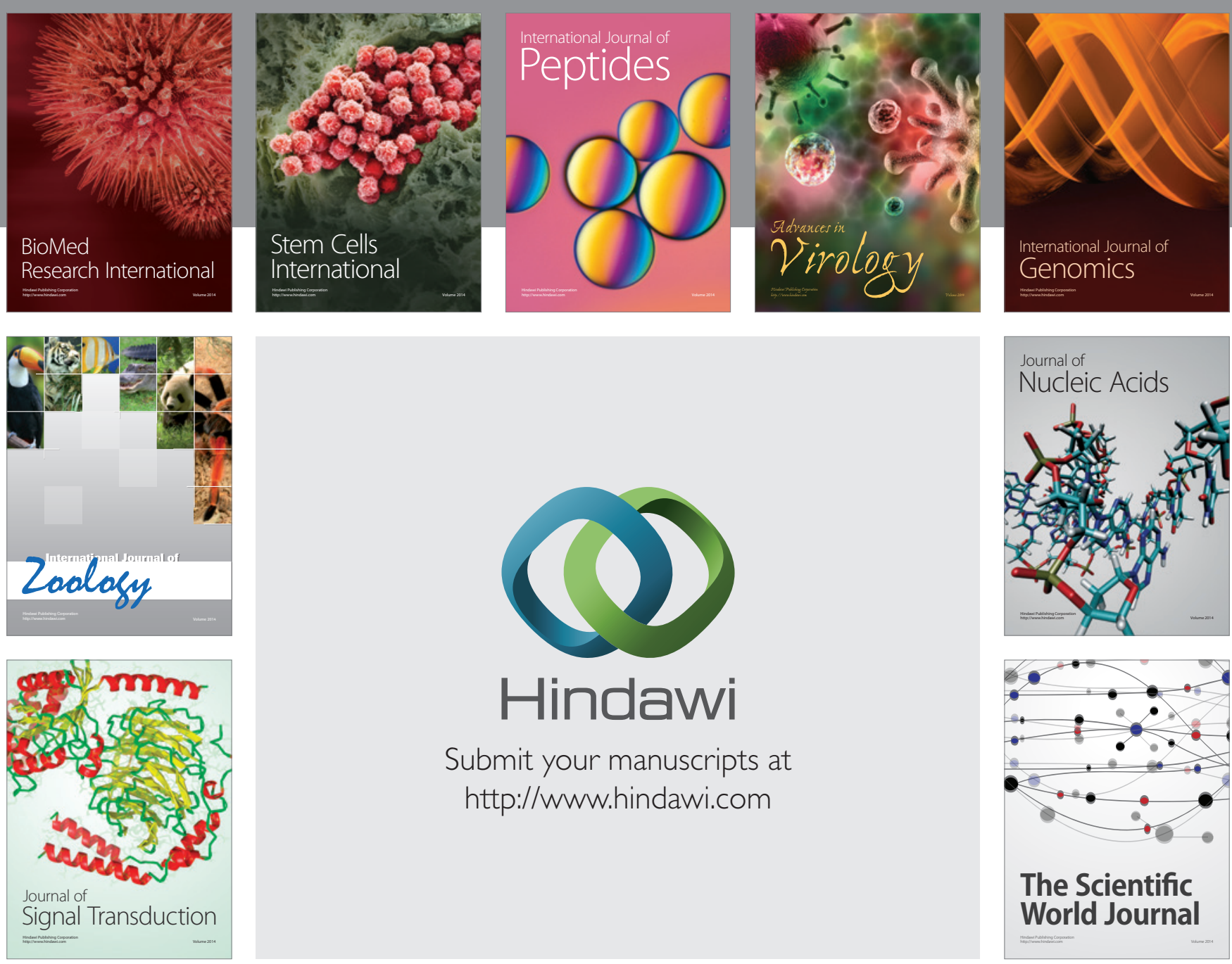

Submit your manuscripts at

http://www.hindawi.com
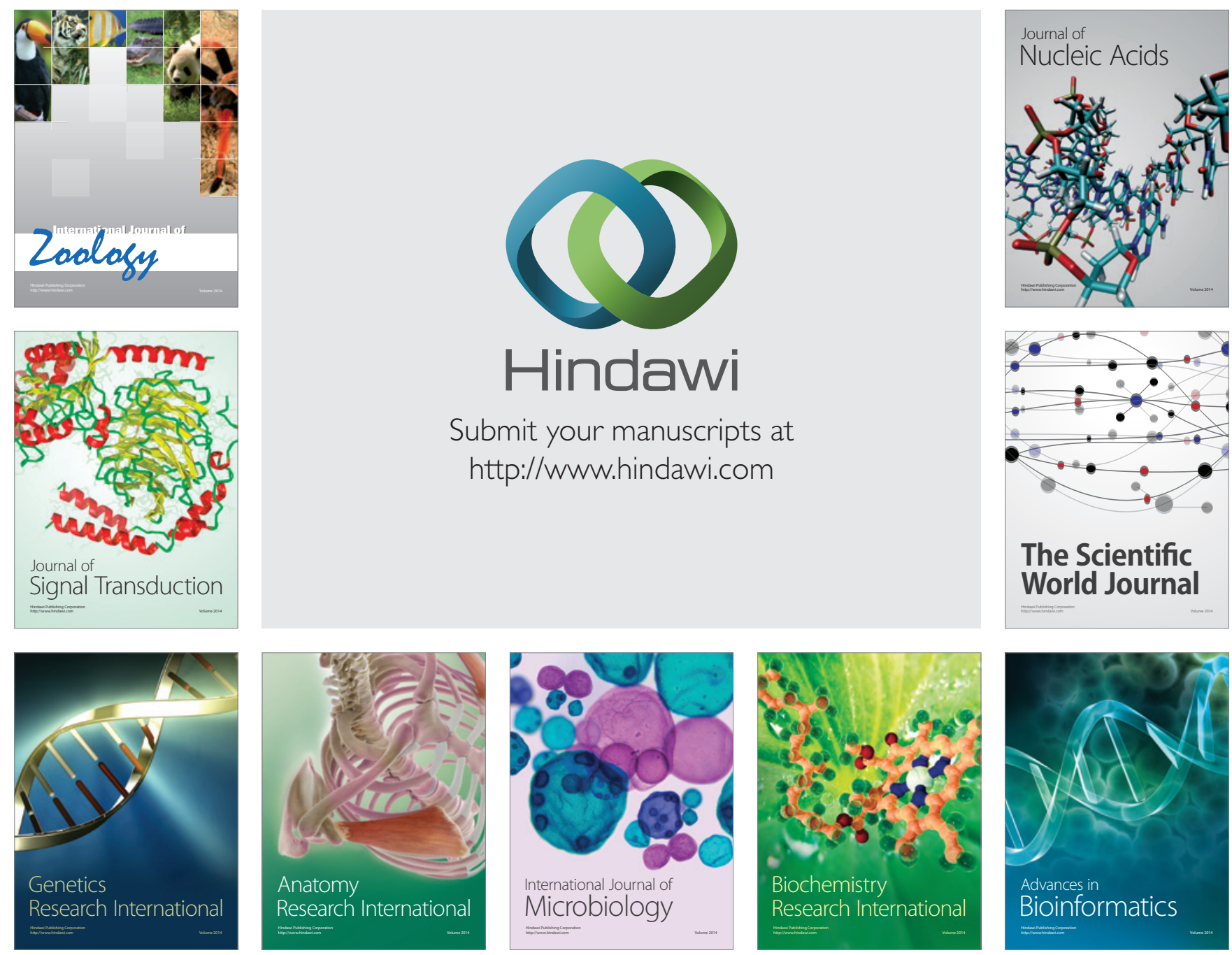

The Scientific World Journal
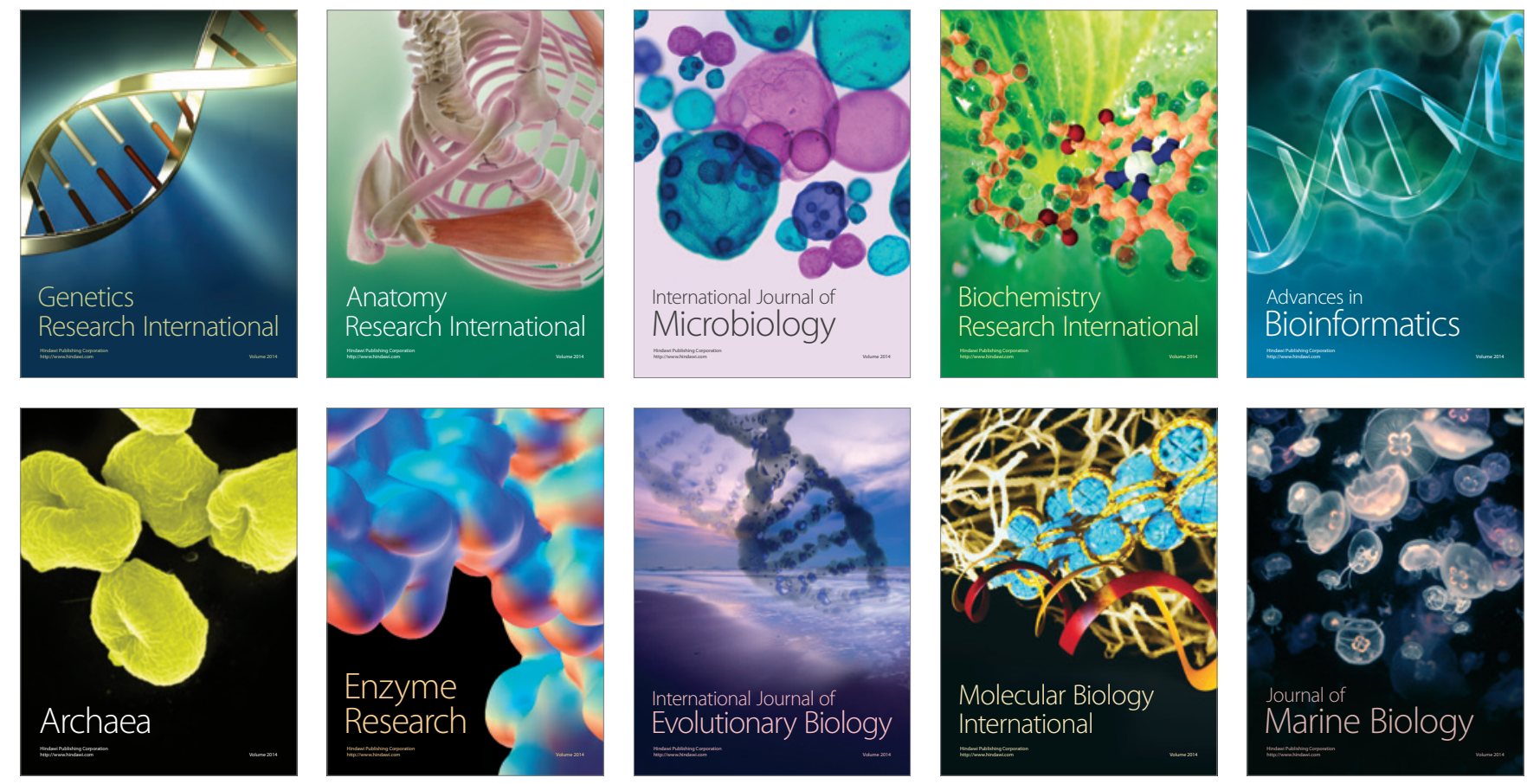